\title{
Perspectives for development of low impact aquaculture in a Western Mediterranean lagoon: the case of the carpet clam Tapes decussatus
}

\author{
L.A. CHESSA ${ }^{1, *}$, F. PAESANTI ${ }^{2}$, A. PAIS ${ }^{1}$, M. SCARDI ${ }^{3}$, \\ S. SERRA ${ }^{1}$ and L. VITALE ${ }^{1}$ \\ ${ }^{1}$ Dipartimento di Scienze Zootecniche, Università di Sassari, Via E. De Nicola, 9, 07100 \\ Sassari, Italy; ${ }^{2}$ Goro Acquicoltura s.r.l., Via G. Carducci, 16, 44020 Goro, Italy; ${ }^{3}$ Di- \\ partimento di Biologia, Università di Roma "Tor Vergata", Via della Ricerca Scientifica, \\ 00133 Roma, Italy; *Author for correspondence (e-mail: chessa@uniss.it; phone: \\ +39-079-229306; fax: + 39-079 229302)
}

Received 15 October 2003; accepted 24 February 2004

\begin{abstract}
Some 30,000 specimens of the Mediterranean clam Tapes decussatus were suspended in nylon bags of two different mesh sizes and pre-grown in the Calich lagoon (Sardinia, Italy) from March to June 2001. The samples differed in size at the end of the pre-growth stage. They were then sown at a density of 650 specimens $\mathrm{m}^{-2}$ in two stations of the lagoon. The growth rates in the stations were different according to the Von Bertalanffy model. Primary and secondary plankton production was calculated by field measurements as well as by modelling. The results indicate that the Calich lagoon could produce a maximum of $753.25 \mathrm{~g} \mathrm{~m}^{-2} \mathrm{yr}^{-1} \mathrm{WW}$, with shell, for Tapes decussatus. Our culture experiments lasted 15 months with an estimated mortality of $50 \%$ and the yield of $T$. decussatus was 4.3 times greater than the calculated natural production.
\end{abstract}

Key words: Coastal lagoons, Mediterranean sea, Mollusc culture, Tapes decussatus

\section{Introduction}

Clam aquaculture has developed greatly in Europe in recent decades. Production increased from around $14,000 \mathrm{mt}$ in 1988 to $55,000 \mathrm{mt}$ in 1997, with a peak of 76,000 $\mathrm{mt}$ in 1995 . Mediterranean aquaculture still focuses mainly on mollusc production (53.9\%). From 1995 to 1999 total mollusc production grew by $3.9 \%$ a year (FAO online database). This was mainly because the Japanese carpet shell, or Manila clam (Tapes philippinarum Adams \& Reeve), replaced the grooved carpet shell (Tapes decussatus L.), the usual European species. The former is more robust and grows more quickly (Mann 1979; Breber 1985; Varadi et al. 2001). In 1983, T. philippinarum was introduced into Northern Adriatic 
lagoons in Italy, rapidly propagated in natural beds and was intensively exploited (Paesanti and Pellizzato 1994). From 1988 to 1993 Italian production of this species increased astonishingly from 1937 to 21,700 $\mathrm{mt}$ (Geri et al. 1996). In 1997, 73\% of the total European production was in Italy. Today this is one of the most important monospecific products of Italian fisheries with about $60,000 \mathrm{mt}$ year ${ }^{-1}$ being produced (Orel et al. 1998).

The Regional Governments of Galicia (Spain) and Sardinia (Italy) have banned the semi-extensive use of Manila clam seed on beaches and lagoons, and several Authorities and Scientific Institutions are actively promoting the use of the native clam (Cannas et al. 1998; Chessa et al. 1998; Marano et al. 1998).

In the Calich lagoon (NW Sardinia, Italy) Chessa et al. (1999) took a census and studied the population dynamics of some edible molluscs species. In addition, Chessa et al. (2001) carried out a comprehensive ecological study of the sustainable level of fish production and the fate of primary and secondary production.

This research compares the yield of low impact aquaculture of $T$. decussatus grown for 15 months in the Calich lagoon with the maximum potential yield for this species, calculated from primary production.

\section{Materials and methods}

The Calich lagoon (NW Sardinia, Italy; Figure 1) is a typical Mediterranean lagoon of 97 ha, with a watershed area of about 42,500 ha. Seawater enters and leaves the lagoon through a narrow channel located in its South-Western part.

Some 30,000 specimens of $T$. decussatus between 6 and $10 \mathrm{~mm}$ in length (mean $7.94 \pm 1 \mathrm{~mm}$ ) were pre-grown suspended in nylon bags of two different mesh sizes: $1.5 \mathrm{~mm}$ (two bags) and $2 \mathrm{~mm}$ (four bags). Pregrowing started late March 2001 near the mouth of the lagoon (hereafter Station 1, Figure 1). At the end of the pre-growing phase (late May 2001), the total length of oro-aboral axis (TL, in $\mathrm{mm}$ ) and total weight (TW, in g) with shell of about 200 molluscs were monitored. The seeds were then sown at a density of 650 specimens $\mathrm{m}^{-2}$ both in Station 1 and in another site in the internal portion of the lagoon (hereafter Station 2, Figure 1). From July 2001 to May 2002, the growth of T. decussatus was evaluated every 2 months by measuring TL and TW of $\sim 120$ specimens per station. Water temperature, dissolved oxygen, salinity and $\mathrm{pH}$ were monitored monthly by means of a multi-parametric probe (data not reported). 


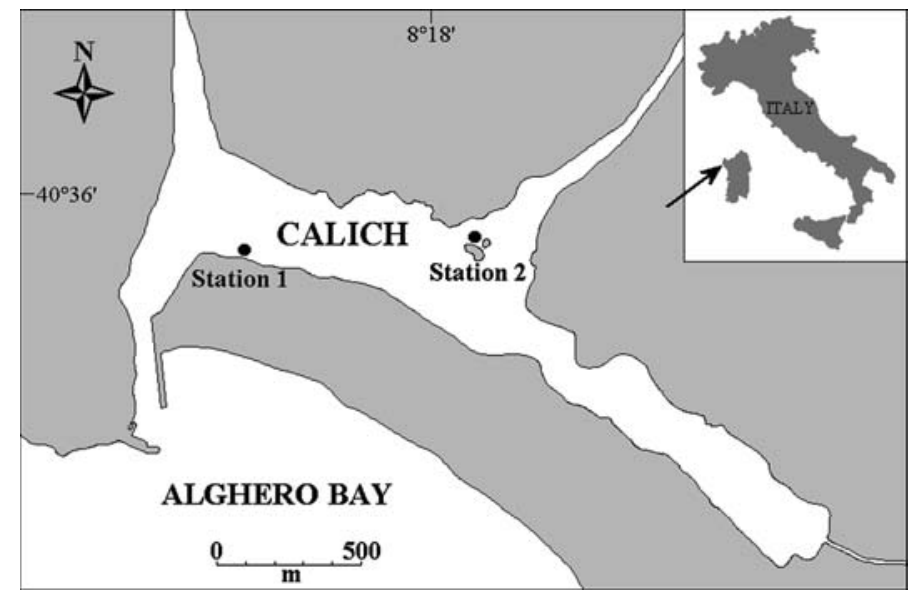

Figure 1. Map of study area and station locations.

The mean averages of shell length (oro-aboral axis) in the two stations were compared using the Mann-Whitney U-test (Siegel 1956) on independent samples. This non-parametric test was selected because shell size distributions significantly deviated from normality. The Bartlett test (Snedecor and Cochran 1989) was applied to test the homogeneity of variances before comparing samples.

The classic Von Bertalanffy $(1938,1960)$ function:

$$
L(t)=L_{\infty}-\left(L_{\infty}-L_{0}\right) \mathrm{e}^{-k t}
$$

was used for the growing pattern. This function describes the increase in length of an organism, over time. The Von Bertalanffy model was used in two different ways. In the first case all three parameters were estimated, while in the second case the asymptotic length value $\left(\mathrm{L}_{\infty}\right)$ was fixed a priori at $65 \mathrm{~mm}$ in order to optimize the other parameters, and so obtain the best total agreement, in terms of mean quadratic error, for the lengths. In both cases, the values of the parameters were estimated using the "genfit" function of Mathcad 2001 software package (Mathsoft Engineering \& Education Inc.). This is a method based on partial derivatives with respect to the parameters to be estimated.

Phytoplankton primary production was recorded by measuring fluorescence and photosynthetic efficiency with a fluorimeter in situ, and by two model outputs. The first was an analytical and deterministic model based on four stated variables: phytoplankton biomass, herbivorous zooplankton biomass, suspended organic matter (particulate and dissolved), and inorganic nitrogen (Scardi et al. 1998). This method has been extensively tested in many cases, in particular in brackish 
semi-closed environments (Kremer and Nixon 1978). The maximum growth rate of the phytoplankton biomass (which depends on temperature) has been corrected for the function of the incident light (Eppley 1972). The second model used for the evaluation of phytoplankton primary production was an empirical model based on neuronal networks (Scardi 1996; Scardi and Harding 1999).

\section{Results and discussion}

The very accurate length-weight relationship $\left(\mathrm{W}=0.000258 \mathrm{~L}^{2.900471}\right.$, $F=201619.8, P<0.001$ ), calculated at the end of the experiment, permits the single variable "length" to be used to describe both size and growth.

The two pre-grown samples were very different in size because of mesh size. Indeed the average shell length was much larger when a wide mesh was used (Figure 2). The difference in shell length depending on mesh size was highly significant according to the Mann-Whitney U-test $(P<0.001)$. This evidence strongly supports the hypothesis that mesh size plays a major role during the first phase of the shell growth.

A comparison between shell lengths in the 2 sites is shown in Figure 3. The Mann-Whitney tests showed that the differences between independent samples collected in the two stations became significant
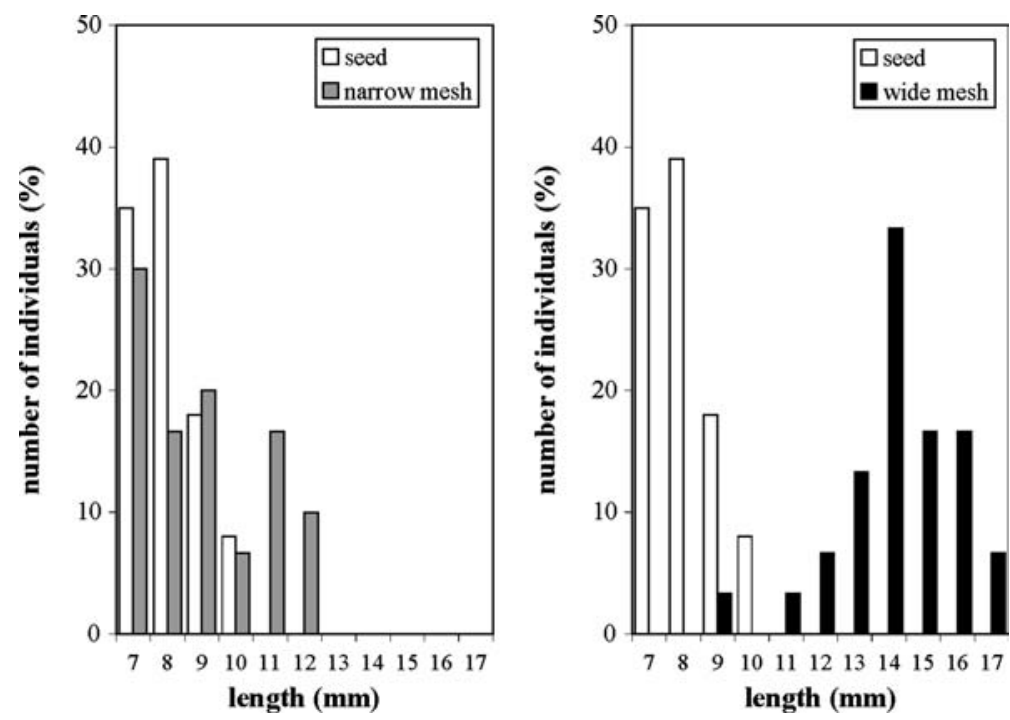

Figure 2. Pre-growth of $T$. decussatus with different mesh sizes in the Calich lagoon. 

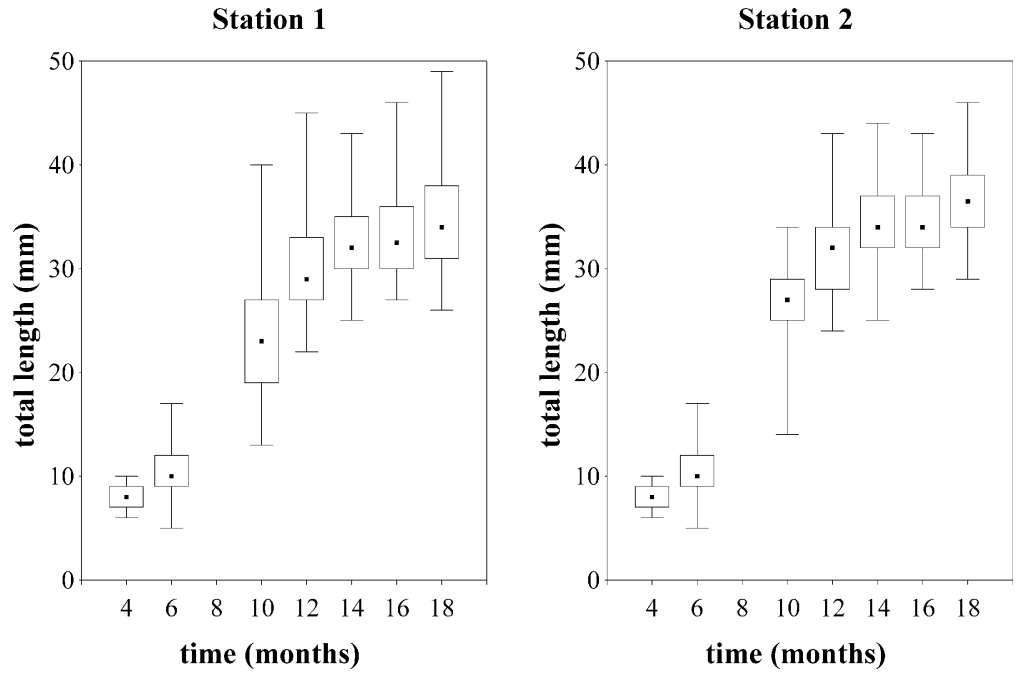

Figure 3. Boxplots of $T$. decussatus growth in the two stations. Values are median (point), 1st and 3rd quartiles (box) and $\mathrm{min} / \max$ values (whiskers).

$(P<0.01)$ from the 10th month on (see the Five boxes on the right in each plot in Figure 3).

The estimates for the Von Bertalanffy model (Figure 4) show that the growth rates in the two stations were marginally different. However the second site (Station 2) is characterized by a lower asymptotic length than the first (Station 1), where the value for growth rate was constantly lower (Table 1).

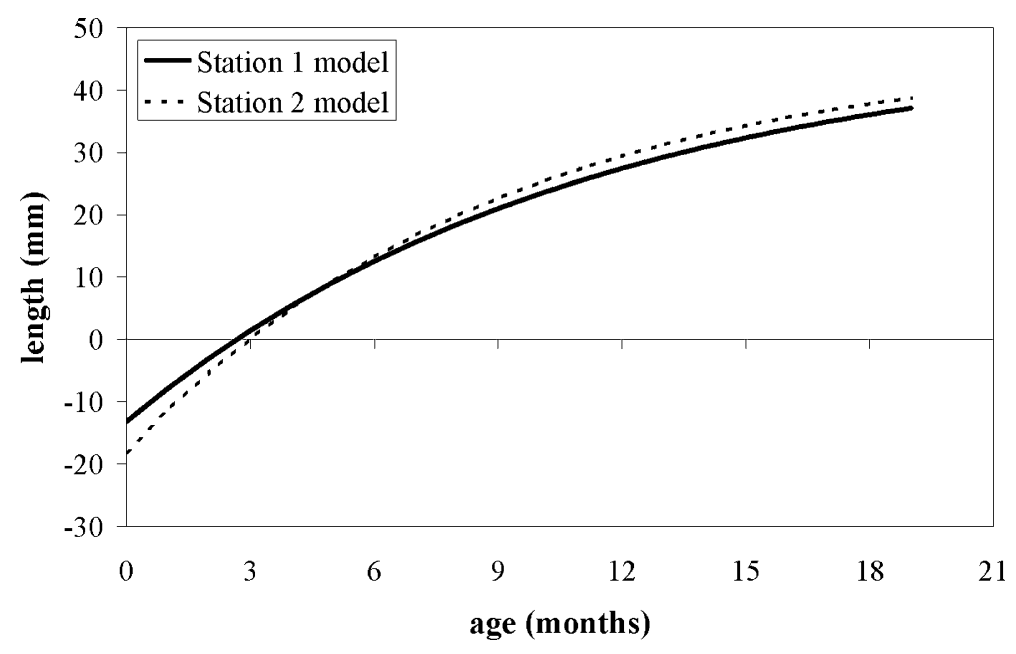

Figure 4. Von Bertalanffy growth model of $T$. decussatus in the two stations. 
Table 1. Parameters of the Von Bertalanffy model for T. decussatus in the two stations

\begin{tabular}{lccccc}
\hline & Station 1 & & \multicolumn{2}{l}{ Station 2} \\
\cline { 2 - 3 } \cline { 5 - 6 } & Estimated $L_{\infty}$ & Fixed $L_{\infty}$ & & Estimated $L_{\infty}$ & Fixed $L_{\infty}$ \\
\hline$L_{\infty}$ & 47.949 & 65.000 & & 46.744 & 65.000 \\
$L_{0}$ & -13.187 & -7.546 & & -18.101 & -9.410 \\
$K$ & 0.091 & 0.053 & & 0.110 & 0.059 \\
\hline
\end{tabular}

Average net primary phytoplankton production (Figure 5) is $240 \mathrm{~g} \mathrm{C} \mathrm{m}^{-2}$ year $^{-1}$ (Chessa et al. 2001). Assuming a prudential conversion ratio of $1: 20$, and considering that an adult specimen is equivalent to $0.18 \mathrm{~g} \mathrm{C}(1 \mathrm{~g} \mathrm{WW}=0.16 \mathrm{~g}$ AFDW; $1 \mathrm{~g} \mathrm{AFDW}=0.45 \mathrm{~g} \mathrm{C})$ (Thorson 1957; Crisp 1984), the lagoon could produce a maximum of $753.25 \mathrm{~g} \mathrm{~m}^{-2}$ year $^{-1} \mathrm{WW}$ with shell of $T$. decussatus.

These aquaculture experiments lasted 15 months with an estimated mortality of $50 \%$, and $114.57 \mathrm{~g} \mathrm{AFDW} \mathrm{m}^{-2}$ year $^{-1}$ of adult specimens $(39.53 \mathrm{~mm})$ were produced, equal to $51.55 \mathrm{~g} \mathrm{C} \mathrm{m}^{-2}$ year $^{-1}$ (i.e. $3236.32 \mathrm{~g}$ of WW with shell).

Bivalve culture consumes nutrients from the marine food web. If too much carbon and nitrogen is removed from the water column, biodiversity can be affected. These chemicals are less available for herbivores

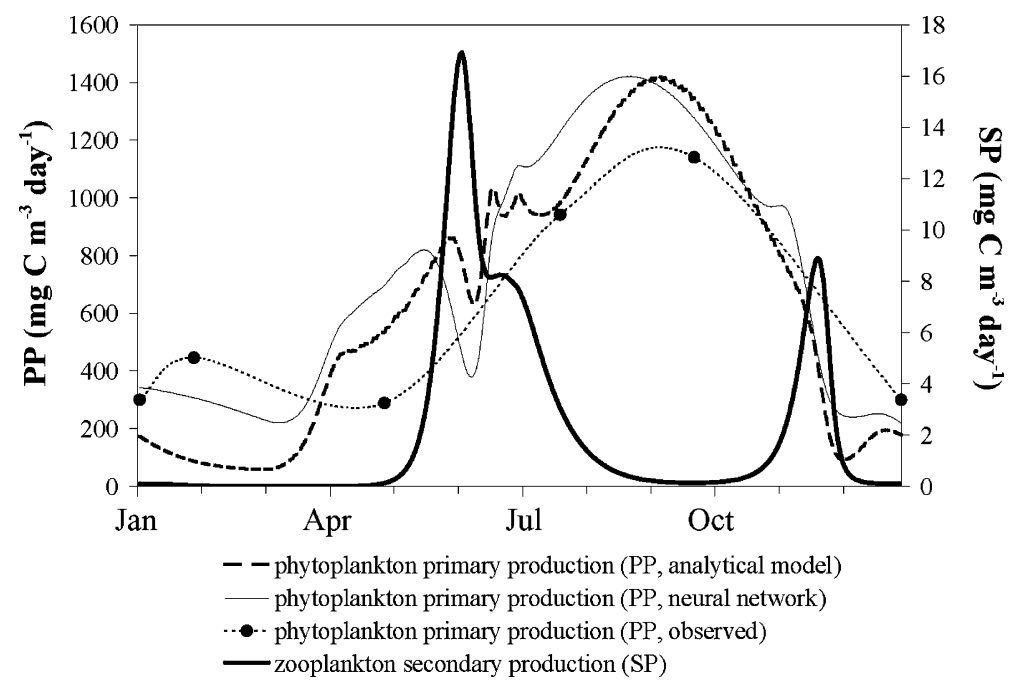

Figure 5. Primary and secondary planktonic production in the Calich lagoon. 
and phytoplankton, and this can affect the growth and reproduction of zooplankton and other herbivores. Bivalves take suspended seston and change it into denser particles that fall to the bottom. Thus permanent extensive Bivalve culture may cause changes in the coastal food web, altering the ecological processes. By contrast, in tidal ponds the inflows may contain considerable quantities of organic matter. This may add to the load of solid and dissolved wastes in effluents from these ponds, as does unused primary production (Pillay 1992).

Our yield in the Calich lagoon for T. decussatus was 4.3 times greater than the calculated natural production. Considering that industrial production of Tapes in Italy ranges between 5000 and 10,000 $\mathrm{g} \mathrm{WW} \mathrm{m}^{-2}$ year ${ }^{-1}$ with shell (Paesanti pers. comm.), this practice may be seen as a low impact culture that allows a weighted use of the primary production of the lagoon and of the surplus of seston present. Moreover, Chessa et al. (1999) pointed out that the natural population of T. decussatus in the Calich lagoon had very low density (from 1.2 to 12.2 specimens $\mathrm{m}^{-2}$ ), especially when compared with another commercial Bivalve such as Cerastoderma glaucum (from 6.1 to 61.2 specimens $\mathrm{m}^{-2}$ ).

\section{Conclusions}

The high phytoplankton primary production in the Calich lagoon cannot be fully exploited for the natural production of high economic value resources like $T$. decussatus. The low impact aquaculture practice described in this paper allows this primary production surplus to be used to produce valuable biomasses that are, at present, scarce in the lagoon. In particular, the controlled cultivation of $T$. decussatus is shown to produce an exceptional answer in terms of size increase. This low impact aquaculture practice can be seen as a possible source of economic benefits for fishermen but, above all, as a regulatory measure which can help to conserve the environment of the lagoon.

\section{Acknowledgements}

This study was supported by Italian MiPAF (Ministero delle Politiche Agricole e Forestali). Many thanks are due to Gesumino Spanu for his invaluable technical assistance, to two anonymous referees for their constructive comments on an earlier version of the manuscript; and to Peter Norton for improving the English version of the text. 


\section{References}

Bertalanffy, L. von 1938. A quantitative theory of organic growth (Inquiries on growth laws. II). Human Biology 10: 181-213.

Bertalanffy, L. von 1960. Principles and theory of growth. In: Wowinski, W.W. (ed.), Fundamental Aspects of Normal and Malignant Growth. Elseviers, Amsterdam, pp. $137-259$.

Breber, P. 1985. L'introduzione e l'allevamento in Italia dell'arsella del Pacifico Tapes semidecussatus Reeve. Oebalia 11: 675-680.

Cannas, A., Lecca, E., Paesanti, F. and Savarino, R. 1998. Valutazione dello stock dell'arsella Tapes decussatus (Linneo, 1758) a fini gestionali in tre ambienti della Sardegna: Laguna Santa Gilla; Valle di Marceddì, Golfo di Olbia. Biologia Marina Mediterranea 5: 441-443.

Chessa, L.A., Scardi, M., Pais, A., Serra, S., Vitale, L. and Mura, F. 1998. Prove di coltivazione di Tapes decussatus (L.) nello stagno di Calich (Sardegna Nord Occidentale). Biologia Marina Mediterranea 5: 1964-1972.

Chessa, L.A., Pais, A., Scardi, M. and Serra, S. 1999. Distribuzione dei molluschi bivalvi di fondo mobile d'interesse commerciale nel compendio ittico di Calich (Sardegna Nord-occidentale). Biologia Marina Mediterranea 6: 561-565.

Chessa, L.A., Cappuccinelli, R., Casola, E., Lanera, P., Ligios, L., Mura, F., Pais, A., Scardi, M., Serra, S., Plastina, N., Valiante, L.M. and Vinci, D. 2001. Valutazioni della produttività ittica dello stagno di Calich (Sardegna Nord occidentale). Biologia Marina Mediterranea 8: 462-472.

Crisp, D.J. 1984. Energy flow measurements. In: Holme, N.A. and McIntyre, A.D. (eds.). Methods for the Study of Marine Benthos. 2nd edn., Blackwell Scientific Publications, Oxford, pp. 284-372.

Eppley, R.W. 1972. Temperature and phytoplankton growth in the sea. Fisheries Bulletin 70: 1063-1085.

FAO online database: http://www.fao.org/fi/statist/statist.asp.

Geri, G., Parisi, G., Lupi, P., Mecatti, M., Dell'Agnello, M., Gualtieri, M. and Bozzi, R. 1996. Caratteristiche corporee in due specie di vongole [Tapes decussatus L. e Tapes semidecussatus (Reeve)] di taglia commerciale. Zootecnica e Nutrizione animale 22: $103-118$.

Kremer, J.N. and Nixon, S.W. 1978. A Coastal Marine Ecosystem. Ecological Studies. Vol. 24. Springer-Verlag, $217 \mathrm{pp}$.

Mann, R. 1979. The effect of temperature on growth, physiology, and gametogenesis in the Manila clam Tapes philippinarum (Adams and Reeve, 1850). Journal of Experimental Marine Biology and Ecology 38: 121-133.

Marano, G., Casavola, N. and De Zio, V. 1998. Riproduzione artificiale di Venerupis decussata (L.) (Mollusca Bivalvia). Biologia Marina Mediterranea 5: 437-440.

Orel, G., Pessa, G., Pavan, B., Zamboni, R., Ceschia, G., Giorgetti, G. and Zentilin, A. 1998. Prove di allevamento di Tapes philippinarum (Adams \& Reeve, 1850) in una valle da pesca della laguna di Grado (Nord Adriatico). Biologia Marina Mediterranea 5: 1937-1946.

Paesanti, F. and Pellizzato, M. 1994. Tapes philippinarum. ESAV, Padova, 74 pp.

Pillay, T.V.R. 1992. Aquaculture and the Environment. Fishing News Books, Oxford, U.K., 189 pp.

Scardi, M. 1996. Artificial neural networks as empirical models of phytoplankton production. Marine Ecology Progress Series 139: 289-299. 
Scardi, M., Casola, E., Dell'Aquila, M., Lanera, P., Maccaroni, A., Mamone, R., Plastina, N., Rampacci, M., Valiante, L.M., Vinci, D., Casolaro, R., Di Dato, P., Di Nuzzo, F. 1998. Modellizzazione a scopi produttivi di uno stagno costiero salmastro. Biologia Marina Mediterranea 5: 1302-1309.

Scardi, M. and Harding, L.W. 1999. Developing an empirical model of phytoplankton primary production: a neural network case study. Ecological Modelling 120: 213223.

Siegel, S. 1956. Nonparametric Statistics for the Behavioral Sciences. McGraw-Hill, New York, 312 pp.

Snedecor, G.W. and Cochran, W.G. 1989. Statistical Methods. 8th edn. Iowa State University Press, Ames, IA, USA, 503 pp.

Thorson, G. 1957. Bottom communities (sublittoral or shallow shelf). Memoirs of Geological Society of America 67: 461-534.

Varadi, L., Szucs, I., Pekar, F., Blokhin, S. and Csavas, I. 2001. Aquaculture development trends in Europe. In: Subasinghe, R.P., Bueno, P., Phillips, M.J., Hough, C., McGladdery, S.E. and Arthur, J.R. (eds.). Aquaculture in the Third Millennium. Technical Proceedings of the Conference on Aquaculture in the Third Millennium, Bangkok, Thailand, 20-25 February 2000. NACA, Bangkok and FAO, Rome, pp. 397-416. 